Subscriber access provided by Caltech Library

\title{
Article
}

\section{Subtle Changes in Lipid Environment Have Profound Effects on Membrane Oxidation Chemistry} Xinxing Zhang, Kevin M. Barraza, Kathleen T. Upton, and Jesse Lee Beauchamp

J. Am. Chem. Soc., Just Accepted Manuscript • Publication Date (Web): 21 Nov 2018

Downloaded from http://pubs.acs.org on November 21, 2018

\section{Just Accepted}

"Just Accepted" manuscripts have been peer-reviewed and accepted for publication. They are posted online prior to technical editing, formatting for publication and author proofing. The American Chemical Society provides "Just Accepted" as a service to the research community to expedite the dissemination of scientific material as soon as possible after acceptance. "Just Accepted" manuscripts appear in full in PDF format accompanied by an HTML abstract. "Just Accepted" manuscripts have been fully peer reviewed, but should not be considered the official version of record. They are citable by the Digital Object Identifier (DOI®). "Just Accepted" is an optional service offered to authors. Therefore, the "Just Accepted" Web site may not include all articles that will be published in the journal. After a manuscript is technically edited and formatted, it will be removed from the "Just Accepted" Web site and published as an ASAP article. Note that technical editing may introduce minor changes to the manuscript text and/or graphics which could affect content, and all legal disclaimers and ethical guidelines that apply to the journal pertain. ACS cannot be held responsible for errors or consequences arising from the use of information contained in these "Just Accepted" manuscripts. 


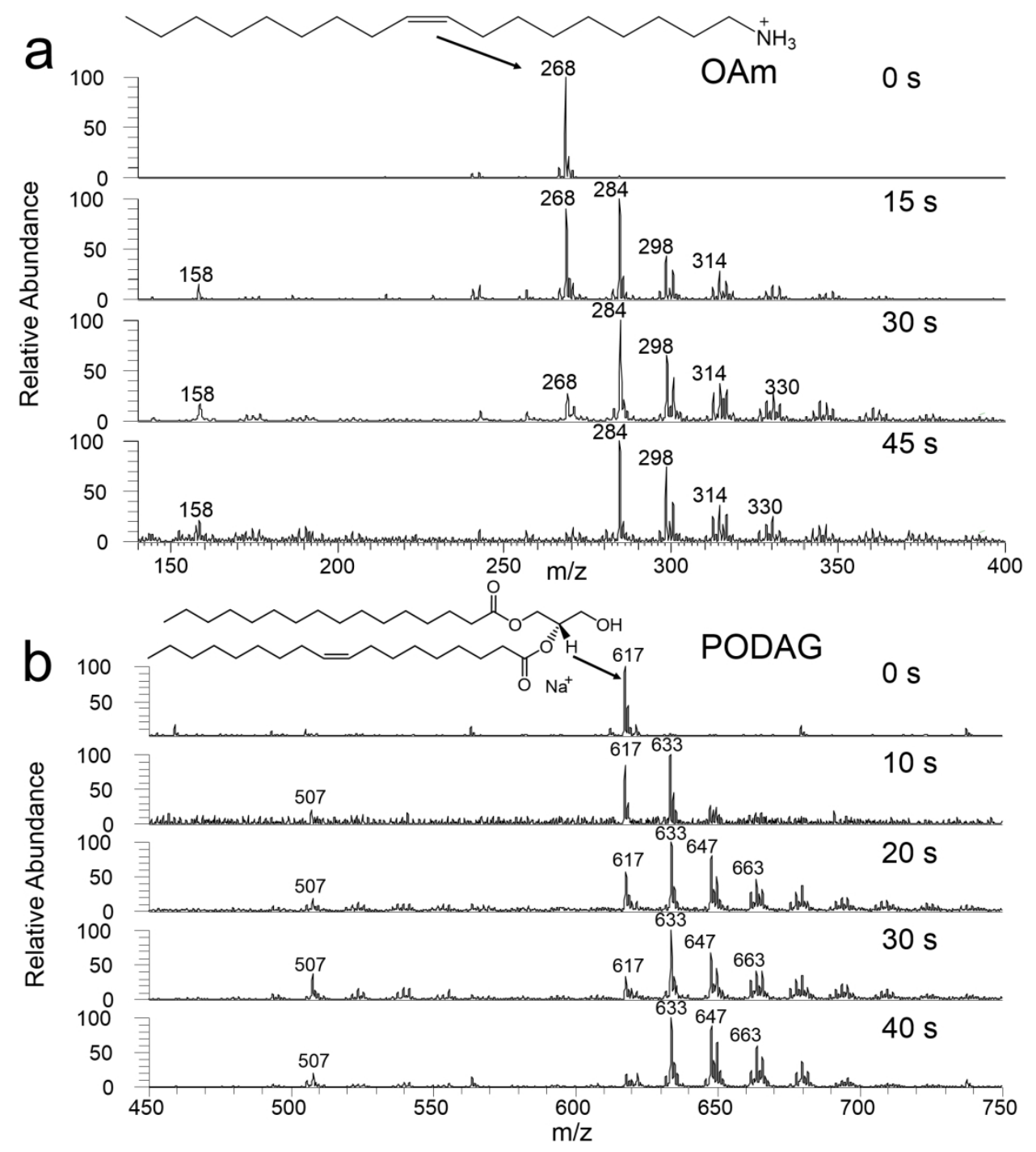

Figure 1

$218 \times 242 \mathrm{~mm}(240 \times 240 \mathrm{DPI})$ 

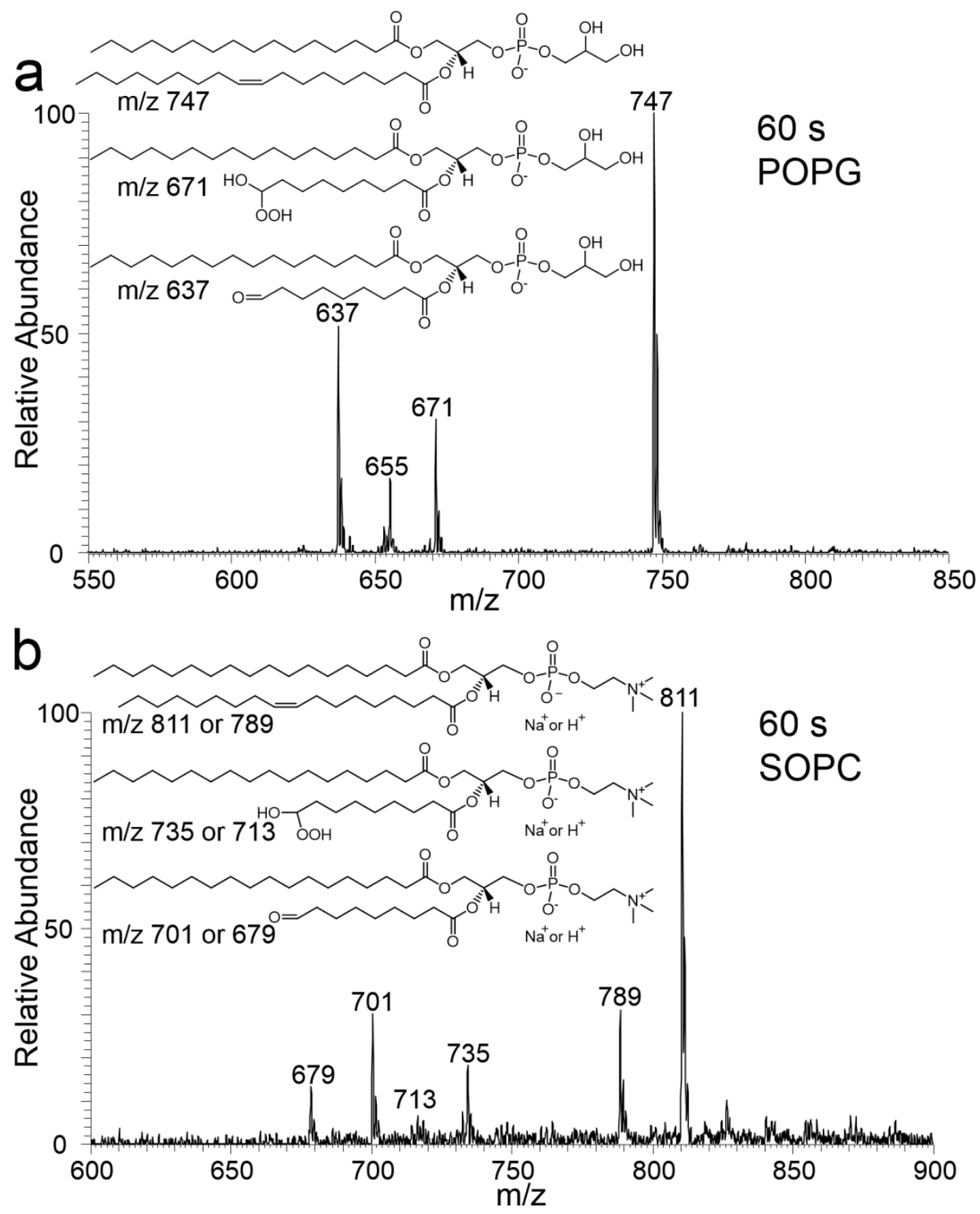

Figure 2

$171 \times 206 \mathrm{~mm}(240 \times 240$ DPI $)$ 


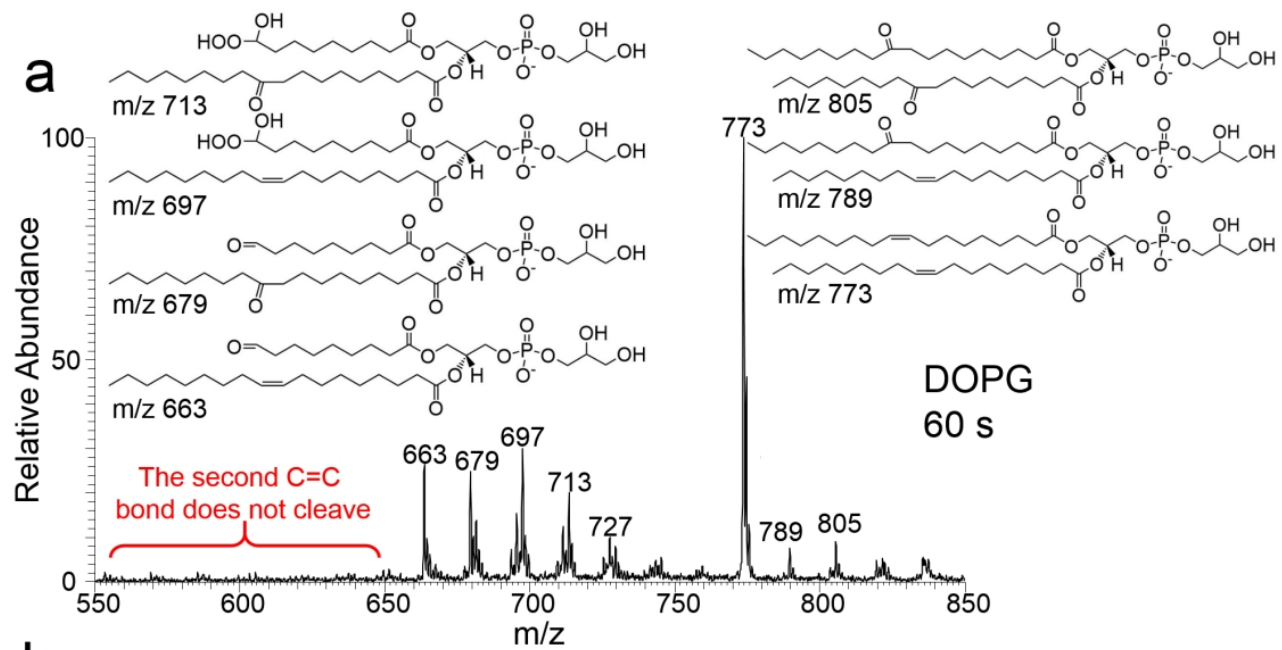

b

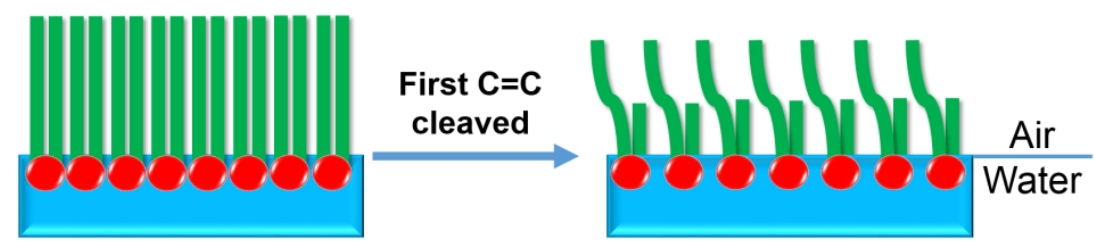

Figure 3

$213 \times 149 \mathrm{~mm}(240 \times 240 \mathrm{DPI})$ 


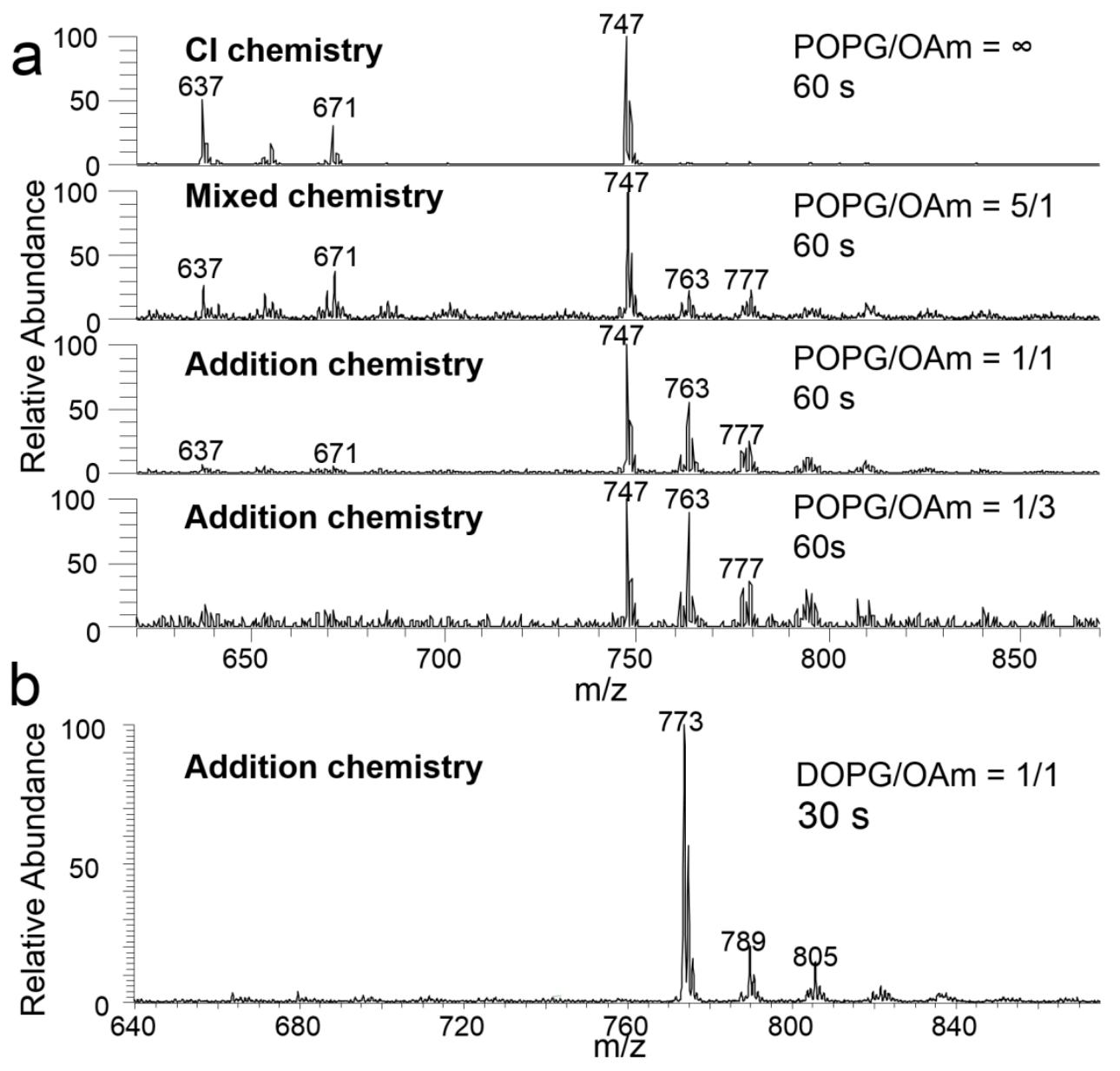

Figure 4

$180 \times 174 \mathrm{~mm}(240 \times 240 \mathrm{DPI})$ 


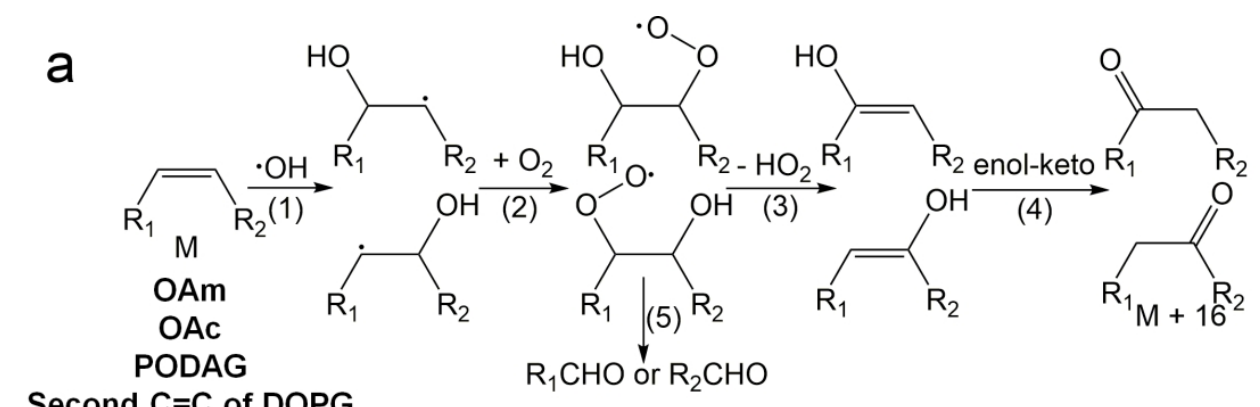

Second $C=C$ of DOPG

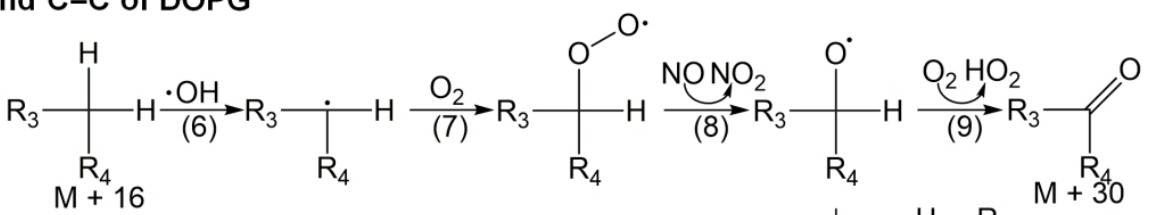

Cl chemistry

Addition chemistry<smiles>[R5]CCCC([R3])C=CCC([R3])=O</smiles>

b

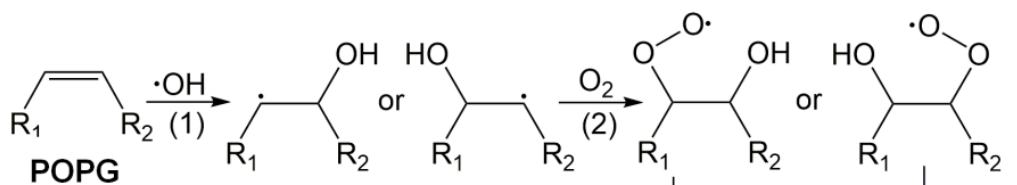
SOPC

First $\mathrm{C}=\mathrm{C}$ of DOPG

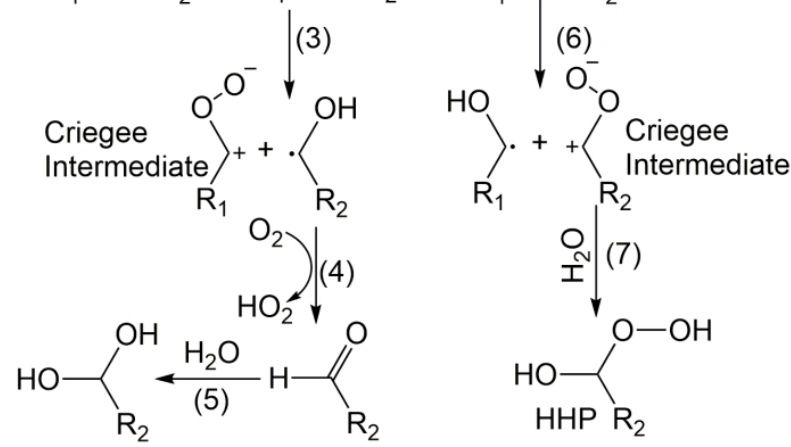

Figure 5

$231 \times 269 \mathrm{~mm}(240 \times 240 \mathrm{DPI})$ 


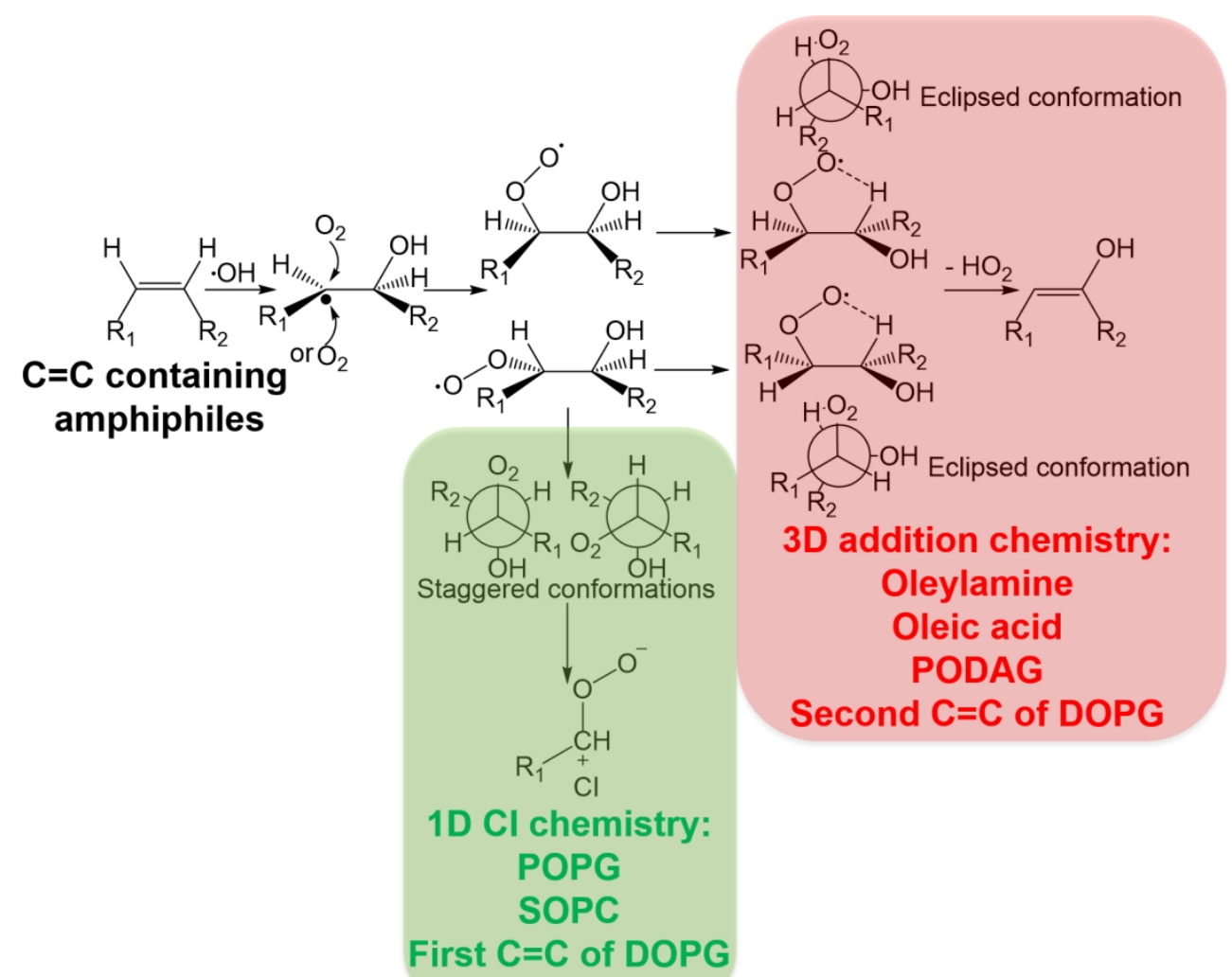

Figure 6

$180 \times 147 \mathrm{~mm}(240 \times 240$ DPI $)$ 


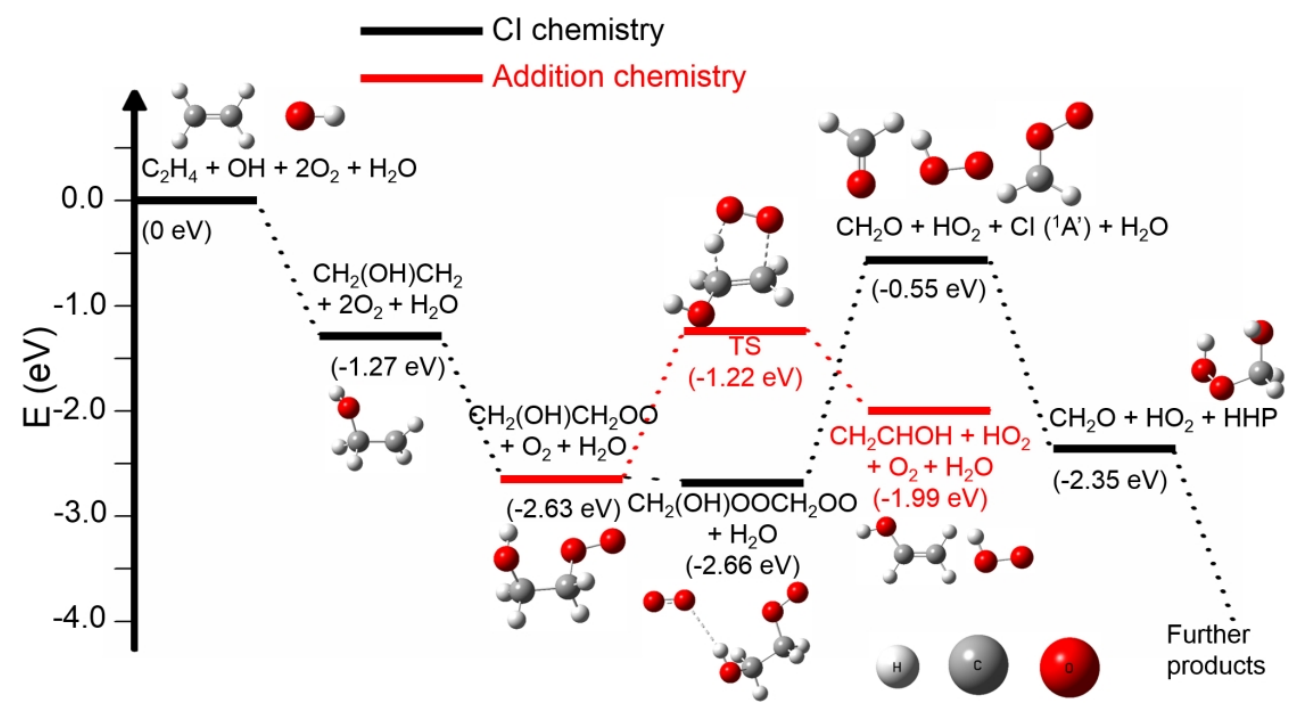

Figure 7

$221 \times 119 \mathrm{~mm}(240 \times 240$ DPI $)$ 


\title{
Subtle Changes in Lipid Environment Have Profound Effects on Membrane Oxidation Chemistry
}

\author{
Xinxing Zhang, $*, \dagger, \ddagger$ Kevin M. Barraza,, Kathleen T. Upton,, and J. L. Beauchamp $*, \ddagger$ \\ $\dagger$ Key Laboratory of Advanced Energy Materials Chemistry (Ministry of Education), College of Chemistry, Nankai \\ University, Tianjin 300071, China. \\ Noyes Laboratory of Chemical Physics and the Beckman Institute, California Institute of Technology, Pasadena, \\ California, 91125, USA.
}

\begin{abstract}
Nature carefully designs the components of amphiphile-composed monolayer and bilayer membranes to deliver specific functions. The compositions of these interfacial layered structures are so delicate that minute modifications can result in huge changes in function. Great efforts have been expended to understand membrane physical properties, with only minimum attention given to associated chemical properties. Here we report the first examples of the delicate chemistry associated with membrane amphiphilic components by studying $\mathrm{OH}$ mediated oxidation of six different unsaturated lipids/surfactants and their mixtures at the air-water interface using field-induced droplet ionization mass spectrometry (FIDI-MS). When the packing is loose or perturbed to be loose by other components or prior chemical modification, the double bond is oxidized without cleavage by adding oxygen functionality. In contrast, compact packing results in double bond cleavage through a Criegee intermediate mechanism. We postulate that constrained environments imposed by lipid packing limit the conformations of the reaction intermediates, controlling reaction pathways.
\end{abstract}

\section{INTRODUCTION}

Monolayer and bilayer structures comprising amphiphilic molecules occur extensively in vivo in the form of various membranes, in the environment as coating of atmospheric aerosols and natural waters, and in condensed phase as dissolved micelles and liposomes. Great efforts are exerted to examine the effect that small structural variations of the molecular components of these interfacial layers have on their physical properties. ${ }^{1-12}$ These physical properties include but are not limited to packing density, curvature, surface pressure, fluidity, and permeability, where a higher packing density can usually result in higher surface pressure, lower fluidity, and lower permeability. An important example is the outermost layer of the eye, known as the tear film. It comprises a complex mixture of lipids residing at the air-water interface, preventing the water layer beneath it from evaporating too fast. ${ }^{3}$ However, the lipid components of dry eye syndrome patients are only slightly different from normal, ${ }^{3}$ providing a testament to their delicate selection by nature. Another example is that cholesterol acts as a bidirectional regulator in cell membranes, where it can increase the packing density and fluidity at the same time by forming tight cholesterol-lipid assemblies, known as lipid rafts. ${ }^{4-6}$ Even though the packing density of amphiphilic molecules can be affected by environmental variables such as pressure and temperature, this property is determined by the structures of the lipids or surfactants and their relative ratios. Tanford ${ }^{7}$ suggests that the head group is the major determinant of packing. A larger hydrophilic head group with more permanent charges usually results in higher packing densities when compared to a smaller head group with fewer or without permanent charges. ${ }^{2,7}$ The former can form more ionic or hydrogen bonding attractions with each other and water, resulting in tight packing. In addition, surfactant chains of lipids with unsaturated $\mathrm{C}=\mathrm{C}$ double bonds are often more loosely packed than those with saturated chains, because the cis-olefin linkage introduces kinks into the otherwise straightened saturated chains. ${ }^{2,} 8-11$ Therefore, packing defects are often associated with lipids and surfactants with small uncharged head groups and unsaturated chains.

While the well characterized physical properties discussed above are indeed critical to determine and maintain the integrity and functions of the monolayer- or bilayer-formed structures, the impact that membrane structure has on associated chemical properties are much less studied or appreciated. This is especially important for biological systems because it is finely tuned biochemical functions that impact health. For example, comprising $30 \mathrm{~mol} \%$ of the lipids in cell membranes, cholesterol serves the biophysical roles of increasing lipid-packing density and maintaining high membrane fluidity. Our group recently demonstrated that this has important biochemical consequences whereby cholesterol plays a non-sacrificial chemoprotective role in lipid monolayers by inhibiting chemical damage by potent reactants such as hydroxyl radical $(\mathrm{OH})$ and $\mathrm{HCl} .^{13}$

Given that investigations addressing the impact of surfactant/lipid composition and packing on membrane chemistry are long overdue, we report herein the $\mathrm{OH}$ mediated oxidation of six different amphiphilic molecules and several of their mixtures at the air-water interface using the homedeveloped field-induced droplet ionization mass spectrometry (FIDI-MS) methodology. This technique is capable of selective "online" sampling of molecules that reside at the airwater interface. These six molecules include oleylamine (OAm), oleic acid (OAc), 1-palmitoyl-2-oleoyl-sn-glycerol 
(PODAG), 1-palmitoyl-2-oleoyl-sn-glycero-3-phospho-(1'rac-glycerol) (POPG), 1-stearoyl-2-oleoyl-sn-glycero-3phosphocholine (SOPC), and 1,2-dioleoyl-sn-glycero-3phospho-(1'-rac-glycerol) (DOPG). All of them have the same reactive functional groups towards $\mathrm{OH}$ oxidation, namely at least one unsaturated $\mathrm{C}=\mathrm{C}$ double bond on an oleyl chain and many saturated $\mathrm{C}-\mathrm{H}$ bonds. The $\mathrm{OH}$ radical is anticipated to exhibit significantly higher reactivity with the $\mathrm{C}=\mathrm{C}$ bond compared to the saturated $\mathrm{C}-\mathrm{H}$ bonds, since the rate coefficients for oxidation of unsaturated hydrocarbons by $\mathrm{OH}$ are significantly higher than corresponding saturated molecules. ${ }^{14}$ These six molecules have very distinct structures (Figure S1): OAm and OAc have one unsaturated chain and small head groups, PODAG has two chains (one unsaturated) with a small head group that does not possess permanent charge, POPG and SOPC have two chains (one unsaturated) with large head groups that have permanent charges, and DOPG has two unsaturated chains with a large head group that has a permanent charge. Hence, it can be expected that OAm, OAc, and PODAG have looser packing, and POPG, SOPC and DOPG have denser packing. Their relative packing densities have been previously reported: ${ }^{15-18}$ the area per lipid (APL) of POPG, SOPC and DOPG ranges from 63 to $70 \AA^{2} /$ lipid (31 to $35 \AA^{2} /$ chain), the APL of PODAG is at least $85 \AA^{2} /$ lipid (42.5 $\AA^{2} /$ chain), and the APLs of OAm and OAc are also around 42 $\AA^{2} /$ chain. So the packing densities of POPG, SOPC and DOPG are indeed higher than those of PODAG, OAm and OAc.

We study monolayers of lipids and surfactants as well as their mixtures at the air-water interface because they are ubiquitous in nature, present as the coating of natural waters, ${ }^{19}$ comprising half of bilayer cell membranes, and the exposed surface of pulmonary alveoli ${ }^{20}$ as well as the tear film ${ }^{3}$ that are directly in contact with air. Hence, amphiphilic monolayers are often the frontier that engages destructive chemical processes. $\mathrm{OH}$ is chosen in this study because it is a potent oxidant that exists both in the atmosphere and in vivo. ${ }^{21-23}$ Once inhaled or generated in vivo, it can rapidly attack virtually all molecules.

\section{EXPERIMENTAL SECTION}

PODAG, POPG, SOPC, and DOPG were purchased from Avanti Polar Lipids (Alabaster, AL, USA) and used without further purification. OAm was purchased from Sigma Aldrich (St. Louis, MO, USA) and used without further purification. All solvents (water and methanol) are HPLC grade and purchased from EMD Chemicals Inc. (Gibbstown, NJ, USA). $2 \mathrm{mM}$ stock solutions of these five molecules are firstly obtained by dissolving the chemicals in methanol, and then diluted by water to make solutions of $100 \mu \mathrm{M}$ pure OAm, PODAG, POPG, SOPC, DOPG, $100 \mu \mathrm{M}$ POPG/20 $\mu \mathrm{M}$ OAm mixture, $100 \mu \mathrm{M}$ POPG/100 $\mu \mathrm{M}$ OAm mixture, $33 \mu \mathrm{M}$ POPG/100 $\mu \mathrm{M}$ OAm mixture, and $100 \mu \mathrm{M}$ DOPG/100 $\mu \mathrm{M}$ OAm mixture solutions.

Figure S2 presents the schematic drawing of the fieldinduced droplet ionization mass spectrometry (FIDI-MS) setup. The FIDI-MS methodology has been proven to be interfacially sensitive, and it selectively samples molecules that are at the air-water interface. ${ }^{24,}{ }^{25}$ Briefly, a hanging droplet of $\sim 2 \mathrm{~mm}$ o.d. ( $\sim \mu \mathrm{L}$ in volume) is suspended on the end of a stainless steel capillary between two parallel plate electrodes separated by $6.3 \mathrm{~mm}$. Droplets are formed from liquid fed through the capillary using a motorized syringe pump. The parallel plates are mounted on a translation stage to allow alignment of an aperture in the electrically grounded plate with the atmospheric pressure inlet of an LTQ-XL mass spectrometer (Thermo-Fisher, Waltham, MA). The capillary is mounted on a separate translation stage to place the droplet exactly midway between the two plates and to align with the inlet of the LTQ-XL. Mass spectrometric sampling of the hanging droplet is accomplished by applying a pulsed high voltage (typically 3 to $5 \mathrm{kV}, 5$ ms duration, polarity selected to sample either positive or negative ions) to the back parallel plate and to the capillary at half the magnitude applied to the back plate to maintain field homogeneity between the front and back plate. When a sufficiently high voltage is applied, bipolar ejection of highly-charged progeny droplets less than 1 $\mu \mathrm{m}$ in diameter from the opposite ends of the suspended droplet ensues. Charged droplets of a selected polarity enter the transfer capillary of the mass spectrometer, resulting in the detection of gas-phase ions. In this study, we apply positive voltage on the back plate in order to detect the protonated OAm, sodiated PODAG, sodiated or protonated SOPC cations and their oxidation products, and negative voltage to detect desodiated POPG, DOPG and their oxidation products. When each droplet is initially formed, we allow 60 seconds for the molecules to diffuse to the air-water interface before exposing the droplet to hydroxyl radicals for a variable reaction time. After the reactions, we trigger the high voltage to sample both reactants and products. Sampling occurs on a millisecond time scale. Each experiment starts with a fresh drop.

Hydroxyl radicals are generated using a dielectric barrier discharge source (DBDS) composed of a borosilicate tube (1/4" OD, 3/16" ID) which acts as the dielectric material. A tungsten filament inner electrode is sealed within the tube, and a conductive silver epoxy coating (McMaster-Carr, Santa Fe Springs, CA, USA) acts as an outer electrode. A glass bubbler provides water saturated helium through the DBDS, with a flow of $1000 \mathrm{~mL} / \mathrm{min}$ monitored by a Type $\pi \mathrm{MFC}$ Digital Mass Flow Controller (Model PFC-50, MKS Instruments). A high voltage AC power supply (Trek PM04015) biased the inner electrode during experiments at $12 \mathrm{kV}$ (peak to peak) and $1000 \mathrm{~Hz}$, while the outer electrode remained grounded. Between the power supply and the tungsten filament, there is a $1 \mathrm{M} \Omega$ resistor used as a current limiter. A low temperature plasma (dielectric barrier discharge) is generated inside the tube, producing hydroxyl radicals in the gas flow. Compared to the tropospheric $\mathrm{OH}$ radical concentration that was measured to be $1-3 \times 10^{6}$ molecules $\mathrm{cm}^{-3}$, 21 the DBDS can generate $\sim 1 \times 10^{9}$ molecules $\mathrm{cm}^{-3} \mathrm{OH}$ radicals ${ }^{26}$ based on the time required to oxidize a monolayer of surfactant with an average of one oxygen per surfactant molecule. The high intensity of $\mathrm{OH}$ radicals significantly accelerates the oxidation process compared to ambient conditions.

\section{Results and Discussion}

Figure 1 presents the time-resolved oxidation of pure OAm and PODAG monolayers for various exposure time periods to $\mathrm{OH}$ radicals at a density of approximately $10^{9} \mathrm{~cm}^{-3}$ in air. The product distributions in these two cases have the same pattern. The m/z 268 peak in Figure 1a is the protonated OAm parent cation, and the $\mathrm{m} / \mathrm{z} 617$ in Figure $1 \mathrm{~b}$ is the sodiated PODAG parent cation. The peaks with higher $\mathrm{m} / \mathrm{z}$ are the oxidation products. In both cases, the oxidation proceeds by a pattern of adding $16 \mathrm{Da}(\mathrm{m} / \mathrm{z} 284$ or 633$), 14 \mathrm{Da}(\mathrm{m} / \mathrm{z} 298$ or 647$)$, and then $16 \mathrm{Da}(\mathrm{m} / \mathrm{z} 314$ or 663$)$. These $\mathrm{m} / \mathrm{z} 284$ or 633 products are initiated by the addition of $\mathrm{OH}$ to the $\mathrm{C}=\mathrm{C}$ bond, followed 
by steps mediated in part by ambient $\mathrm{O}_{2}$ molecules, forming carbonyl functional groups. The other higher $\mathrm{m} / \mathrm{z}$ products are results of oxidation of saturated $\mathrm{C}-\mathrm{H}$ bonds originated by abstraction of hydrogen atoms from $\mathrm{C}-\mathrm{H}$ bonds by $\mathrm{OH}$ radicals, followed by steps mediated by ambient $\mathrm{O}_{2}$ and $\mathrm{NO}$ molecules, forming carbonyl and hydroxyl functional groups (vide infra). Since the major products are the addition of oxygen functionality to the parent molecules, we name this process "addition chemistry". At the lower $\mathrm{m} / \mathrm{z}$ side, both molecules have minor products at $\mathrm{m} / \mathrm{z} 158$ or 507 , resulting from the $\mathrm{C}=\mathrm{C}$ bond being cleaved into an aldehyde group. At $45 \mathrm{~s}$ or $40 \mathrm{~s}$, almost all of the OAm and PODAG are oxidized with the addition of one or more oxygen atoms. The $\mathrm{OH}$ oxidation of OAc has been previously reported by our group, ${ }^{26}$ and the oxidation pattern is similar to OAm and PODAG. The similarity among these three molecules is comprehensible in the sense that they have the same functional groups subject to $\mathrm{OH}$ oxidation, and they are all relatively loosely packed.

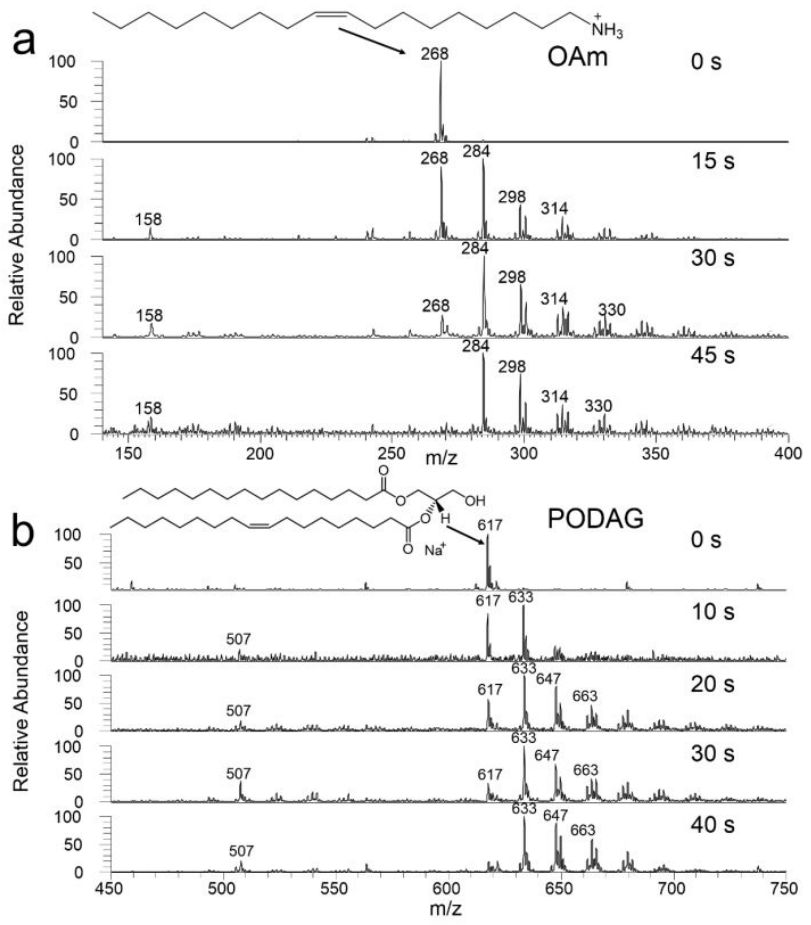

Figure 1. Time-resolved FIDI-MS spectra of the $\mathrm{OH}$ oxidation reactants and products of two surfactants at the air-water interface. (a) Protonated OAm and its oxidation products appear at 268 and higher $\mathrm{m} / \mathrm{z}$. Low abundance bond cleavage products are observed starting at $\mathrm{m} / \mathrm{z}$ 168. (b) Sodiated PODAG and its oxidation products appear at 617 and higher $\mathrm{m} / \mathrm{z}$. Low abundance bond cleavage products are observed starting at $\mathrm{m} / \mathrm{z} 507$.

Figure 2 shows the $\mathrm{OH}$ oxidation of POPG and SOPC for $60 \mathrm{~s}$. The time-resolved study of POPG has been previously reported, ${ }^{13}$ so here we only present a representative spectrum. The $\mathrm{m} / \mathrm{z} 747$ peak in Figure 2a is the desodiated POPG parent anion and the m/z 789 and 811 peaks in Figure $2 \mathrm{~b}$ are the protonated and sodiated SOPC parent cations. Surprisingly, in complete contrast to OAm and PODAG, the oxidation products of POPG and SOPC appear at lower $\mathrm{m} / \mathrm{z}$ where the chemistry is dominated by the highly reactive double bond on the oleoyl chains. The m/z 637 product of POPG and the $\mathrm{m} / \mathrm{z}$ 679 and 701 products of SOPC are results of the double bond cleaved into aldehyde groups. The $\mathrm{m} / \mathrm{z} 671$ peak of POPG and the $\mathrm{m} / \mathrm{z} 713$ and 735 peaks are from the oxidation of the double bond into an hydroxyhydroperoxide (HHP) molecule via a Criegee intermediate $(\mathrm{CI})$ (vide infra). We call the process "CI chemistry". Noteworthy is the fact that CI is an important atmospheric radical resulting from the reaction of ozone with olefins both in the gas phase ${ }^{27}$ and at the air-water interface, ${ }^{28}$ and a major contributor to $\mathrm{OH}$ radicals in the troposphere. ${ }^{29}$ Our results provide evidence that $\mathrm{OH}$ oxidation of tightly packed unsaturated hydrocarbons can also generate CI.
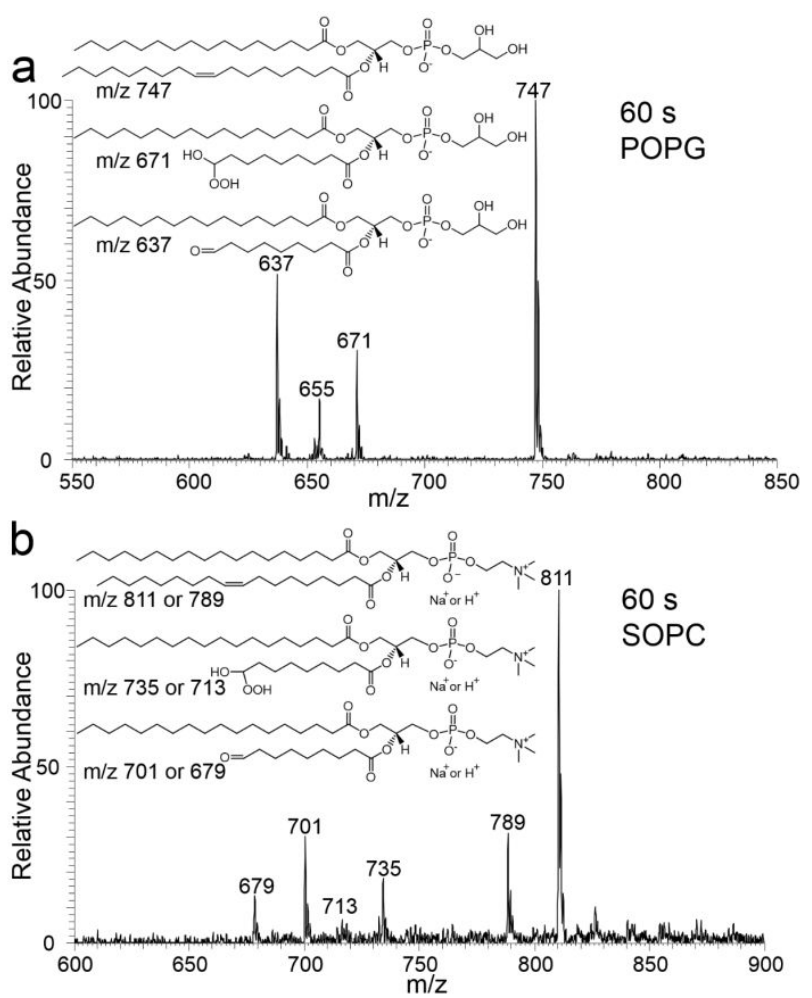

Figure 2. FIDI-MS spectra of the $\mathrm{OH}$ oxidation reactants and products of two phospholipids after $60 \mathrm{~s}$ of oxidation. (a) Desodiated POPG and its oxidation products appear at 747 and lower $\mathrm{m} / \mathrm{z}$. (b) Sodiated/protonated SOPC and its oxidation products appear at $811 / 789$ and lower $\mathrm{m} / \mathrm{z}$.

Since the above discussed molecules all have the same oleyl chain to react with $\mathrm{OH}$, and PODAG, POPG and SOPC have the spectator saturated hydrocarbon chains nearby, the striking difference between the addition chemistry of OAm, OAc and PODAG, and CI chemistry of POPG and SOPC must be attributable to the different packing density. In Figure $3 \mathrm{a}$, we introduce the results of DOPG, a lipid with a large head group and two unsaturated chains. The $\mathrm{m} / \mathrm{z} 773$ peak is the desodiated parent anion. The major products appear at lower $\mathrm{m} / \mathrm{z}$. The $\mathrm{m} / \mathrm{z} 663$ peak is the double bond cleaved into an aldehyde and the $\mathrm{m} / \mathrm{z} 697$ peak is the HHP product, this being the same CI chemistry as observed for POPG and SOPC. However, after the first double bond is cleaved, the second double bond does not cleave into even lower $\mathrm{m} / \mathrm{z}$ products. Instead, it follows the pattern for addition chemistry, resulting in the $\mathrm{m} / \mathrm{z} 679$ (16 Da more than $\mathrm{m} / \mathrm{z} 663$ ) and the $\mathrm{m} / \mathrm{z} 713$ (16 Da more than 697) products. This result further confirms the suggestion that packing density determines the chemistry. Figure $3 \mathrm{~b}$ depicts this process: after losing the company of the first chain that is cleaved through the CI chemistry, the second chain becomes loosely packed, leaving it to follow the addition chemistry reaction path. The fact that the products 
from CI chemistry (m/z 663 and 697) have similar intensity as the products from the addition chemistry $(\mathrm{m} / \mathrm{z} 679$ and 713$)$ also agrees with the suggested reaction sequence with $\mathrm{CI}$ chemistry occurring first, followed by the addition chemistry. The oxidation chemistries of the above discussed six molecules are tabulated in Table 1 along with their relative packing densities.

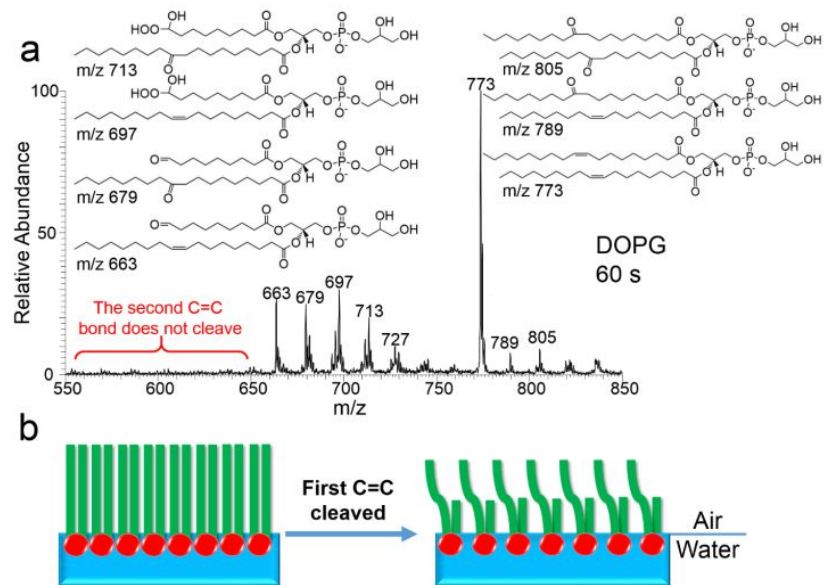

Figure 3. FIDI-MS spectra of the $\mathrm{OH}$ oxidation reactants and products of DOPG after $60 \mathrm{~s}$ of oxidation. (a) Desodiated DOPG and its oxidation products appear at 773 and lower $\mathrm{m} / \mathrm{z}$. Low abundance products are observed at $\mathrm{m} / \mathrm{z}$ higher than 773 . (b) A cartoon showing the packing change of the second chain of DOPG after the chain is cleaved.

Table 1. Areas/chain for a measure of packing density and the oxidation chemistries of the six molecules studied.

\begin{tabular}{|l|l|l|}
\hline Molecule & Packing density $\left(\AA^{2} /\right.$ chain $)$ & Chemistry \\
\hline PODAG & $>42.5^{16}$ & Addition \\
\hline OAc & $42.2^{15}$ & Addition \\
\hline OAm & $40.0^{15}$ & Addition \\
\hline DOPG & $34.7^{17}$ & Mixed \\
\hline POPG & $32.2^{17}$ & $\mathrm{CI}$ \\
\hline SOPC & $31.9^{18}$ & $\mathrm{CI}$ \\
\hline
\end{tabular}

To further test the idea that packing density changes the chemistry, mixtures of OAm with POPG, and OAm with DOPG were studied to see if OAm could perturb the packing of POPG and DOPG. In Figure 4a, results from the $60 \mathrm{~s}$ oxidation of pure POPG, POPG/OAm $=5 / 1,1 / 1$ and $1 / 3$ are presented. When POPG/OAm $=5 / 1$, a mixed chemistry is observed with lower $\mathrm{m} / \mathrm{z}$ products from the CI chemistry and higher $\mathrm{m} / \mathrm{z}$ products at 763 and 777 from the addition chemistry, indicating that POPG packing is already loosened by the addition of only $16.7 \%$ OAm. This suggests a very high sensitivity of the chemistry towards the composition of the monolayer. When POPG/OAm $=1 / 1$ and $1 / 3$, the $\mathrm{CI}$ chemistry is fully inhibited, and only the addition chemistry is observed. The product intensity is higher in the $1 / 3$ case than the $1 / 1$ case, suggesting that higher OAm ratio loosens the monolayer more, giving $\mathrm{OH}$ higher permeability into the interface. As is clearly evident in Figure $4 \mathrm{~b}$, the $1 / 1$ mixture of DOPG and OAm also fully transforms the CI chemistry into the addition chemistry after $30 \mathrm{~s}$ of oxidation.
When the area per lipid is $60 \AA^{2}$, the minimum concentration to form a monolayer lipid at the air-water interface of a $2 \mathrm{~mm}$ o.d. droplet is around $8 \mu \mathrm{M}$, so the 100 $\mu \mathrm{M}$ concentration used in the above experiments is enough to form a monolayer. Since we cannot manually compress the monolayers of OAc or OAm using the current setup, we studied the $\mathrm{OH}$ oxidation chemistry of a $1 \mu \mathrm{M}$ solution of POPG to guarantee a loosely packed monolayer (Figure S3). Addition chemistry is observed, which further supports our conclusion that packing density is a key factor determining the oxidation chemistry. Not unexpectedly, as a result of the relatively low concentration, the signal/noise obviously suffers in Figure S3.

The product yields from $\mathrm{OH}$ oxidation of POPG, SOPC and DOPG are much lower than those of OAm and PODAG, even after longer exposure times. It is understandable that tight packing can lower the oxidation rate by lowering the $\mathrm{OH}$ radical permeability, similar to our earlier reported results for the markedly reduced oxidation of monolayers of lipids mixed with $30 \mathrm{~mol} \%$ cholesterol. ${ }^{13}$ This observation provokes the obvious question as to why does the packing density, a physical property, give completely different chemistries in these seemingly similar reactive systems.

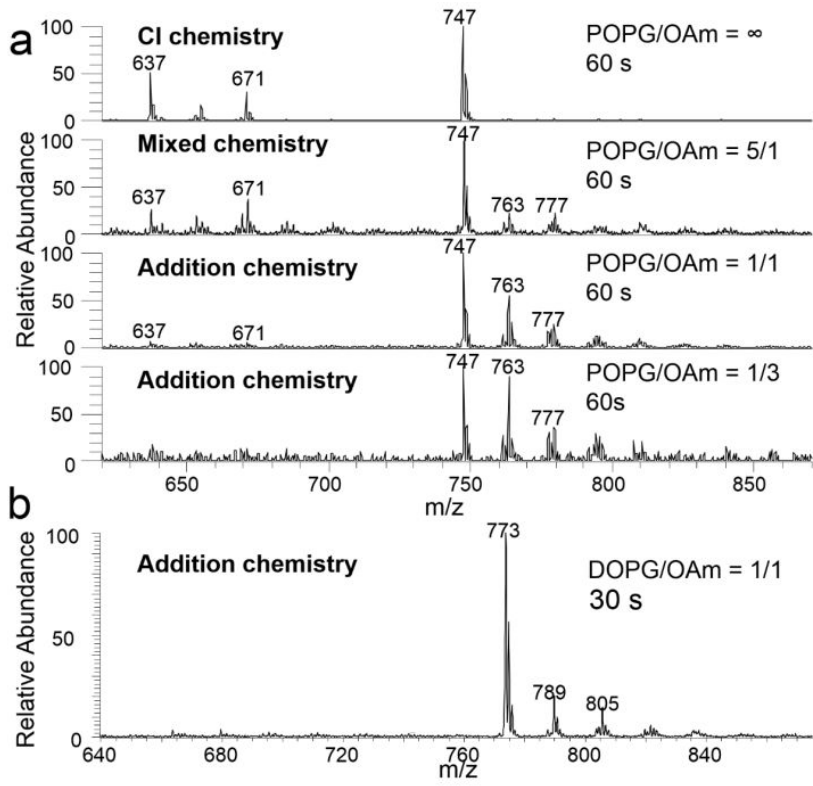

Figure 4. FIDI-MS spectra of the $\mathrm{OH}$ oxidation reactants and products of OAm and phospholipid mixtures. (a) Gradual change of oxidation chemistry of POPG when different amounts of OAm is added to the momolayer. (b) The addition chemistry of DOPG studied in the OAm/POPG mixture.

To answer this question, we first discuss the reaction mechanisms. Figure 5a exhibits the proposed mechanisms of the addition chemistry. It starts with a $\mathrm{C}=\mathrm{C}$ double bond belonging to OAm, OAc, PODAG, the second $\mathrm{C}=\mathrm{C}$ bond in DOPG, or the perturbed POPG and DOPG. Step (1) is the uptake of one $\mathrm{OH}$ radical from the gas phase by either carbon atom on the double bond, forming a $\beta$-hydroxyalkyl radical. This $\mathrm{OH}$ addition step is the well-accepted first reaction of $\mathrm{OH}$ and alkenes. ${ }^{13,30}$ Afterwards, the hydroxyalkyl radical uptakes an $\mathrm{O}_{2}$ molecule to form a hydroxyperoxy radical in step (2) since the concentration of ambient $\mathrm{O}_{2}$ is many orders of magnitude higher than the $\mathrm{OH}$ used in the current study $\left(\sim 1 \times 10^{9}\right.$ molecules $\left.\mathrm{cm}^{-3}\right)$. The peroxy moiety could abstract an 
$\mathrm{H}$ atom on the adjacent carbon, resulting in an $\mathrm{HO}_{2}$ leaving group and an enol product (step (3)). The enol product can undergo step (4), the enol-keto tautomerization, to form a more stable carbonyl group, this being the product 16 Da more than the parent ion, corresponding to $\mathrm{m} / \mathrm{z} 284$ for OAm (Figure 1a), 633 for PODAG (Figure 1b), 679 or 713 for DOPG (Figure 3a), 763 for the disturbed POPG (Figure 4a), and 789 or 805 for the disturbed DOPG (Figure 4b). After step (2), the $\beta$-hydroxyalkyl radical could also undergo a $\mathrm{C}$ - $\mathrm{C}$ bond cleavage (step (5)), resulting in the minor aldehyde products for OAm (m/z 158, Figure 1a) and PODAG (m/z 507, Figure $1 b)$. After the more reactive $\mathrm{C}=\mathrm{C}$ bond is "consumed", the remaining saturated $\mathrm{C}-\mathrm{H}$ bonds come into play. The lower panel of Figure 5a starts from the $\mathrm{M}+16$ species, the product from the oxidation of $\mathrm{C}=\mathrm{C}$ bonds. The reaction starts from an $\mathrm{H}$ atom abstraction by an $\mathrm{OH}$ radical (step (6)), resulting in an alkyl radical, which then uptakes an $\mathrm{O}_{2}$ molecule to form a peroxy radical (step (7)). This peroxy radical can react with ambient $\mathrm{NO}$ to form a $\mathrm{NO}_{2}$ molecule and an alkoxy radical (Step (8)). The NO concentration in Los Angeles area ${ }^{31}$ is typically $\sim 1 \times 10^{11}$ molecules $\mathrm{cm}^{-3}$, much higher than the $\mathrm{OH}$ concentration. The alkoxy radical formed in step (8) will react with an ambient $\mathrm{O}_{2}$ to form an $\mathrm{HO}_{2}$ leaving molecule and another carbonyl group, this being further $14 \mathrm{Da}$ more than the $\mathrm{M}+16$ molecule, corresponding to the $\mathrm{m} / \mathrm{z} 298$ peak for OAm (Figure 1a), 647 for PODAG (Figure 1b), 693 or 727 for DOPG (Figure 3a), and 777 for the disturbed POPG (Figure 4a). Since these are loosely packed monolayers, the alkoxy radical formed in step (8) could also undergo an isomerization (hydrogen atom transfer) through a six-member ring, ending up as a $\gamma$-hydroxyalkyl radical in step (10). This alkyl radical can repeat step (7) to step (9) to add another carbonyl group, accountable for the $\mathrm{M}+46$ Da products, corresponding to $\mathrm{m} / \mathrm{z}$ 314 peak for OAm (Figure 1a) and 663 for PODAG (Figure 1b). Since these molecules have copious $\mathrm{C}-\mathrm{H}$ bonds, further oxidation will repeat the above processes, resulting in more additions of hydroxyl and carbonyl groups. These proposed mechanisms are well documented in previous studies. ${ }^{13,26,30-35}$

Figure $5 \mathrm{~b}$ presents the proposed mechanism of the $\mathrm{CI}$ chemistry of POPG, SOPC and the first $\mathrm{C}=\mathrm{C}$ bond of DOPG. Step (1) and (2) are the same as the addition chemistry, forming two different $\beta$-hydroxyperoxy radicals, one of which can undergo $\beta$-cleavage to an $\alpha$-hydroxyalkyl radical (step (3)), and the latter can further react with $\mathrm{O}_{2}$ to form an $\mathrm{HO}_{2}$ leaving group and an aldehyde molecule, corresponding to $\mathrm{m} / \mathrm{z}$ 637 for POPG (Figure 2a), 679 or 701 for SOPC (Figure 2b), and 663 for DOPG (Figure 3a). The aldehyde reacts with $\mathrm{H}_{2} \mathrm{O}$ to form the minor hemiacetal product ( $\mathrm{m} / \mathrm{z} 655$ for POPG and 681 for DOPG). The second $\beta$-hydroxyperoxy radical formed in step (2) can also undergo thermal dissociation into a Criegee intermediate $(\mathrm{CI})$ and a hydroxyalkyl radical (step (6)). This CI product, written in its favored zwitterionic form, can react with the $\mathrm{CI}$ scavenger, $\mathrm{H}_{2} \mathrm{O}$, to form the hydroxyhydroperoxide (HHP) product (step (7)), corresponding to $\mathrm{m} / \mathrm{z} 671$ for POPG (Figure 2a), 713 or 735 for SOPC (Figure 2b), and 697 for DOPG (Figure 3a). The HHP product is a symbolic evidence of the CI reaction pathway ${ }^{36}$ and eventually becomes an abundant product. This mechanism for generation of $\mathrm{CI}$ from reaction of $\mathrm{OH}$ with olefins was first proposed in our previously reported reaction of POPG and $\mathrm{OH},{ }^{13}$ where expected products from several $\mathrm{CI}$ scavengers ${ }^{37}$ were observed, and $a b$ initio calculations were performed to justify the proposed mechanism.

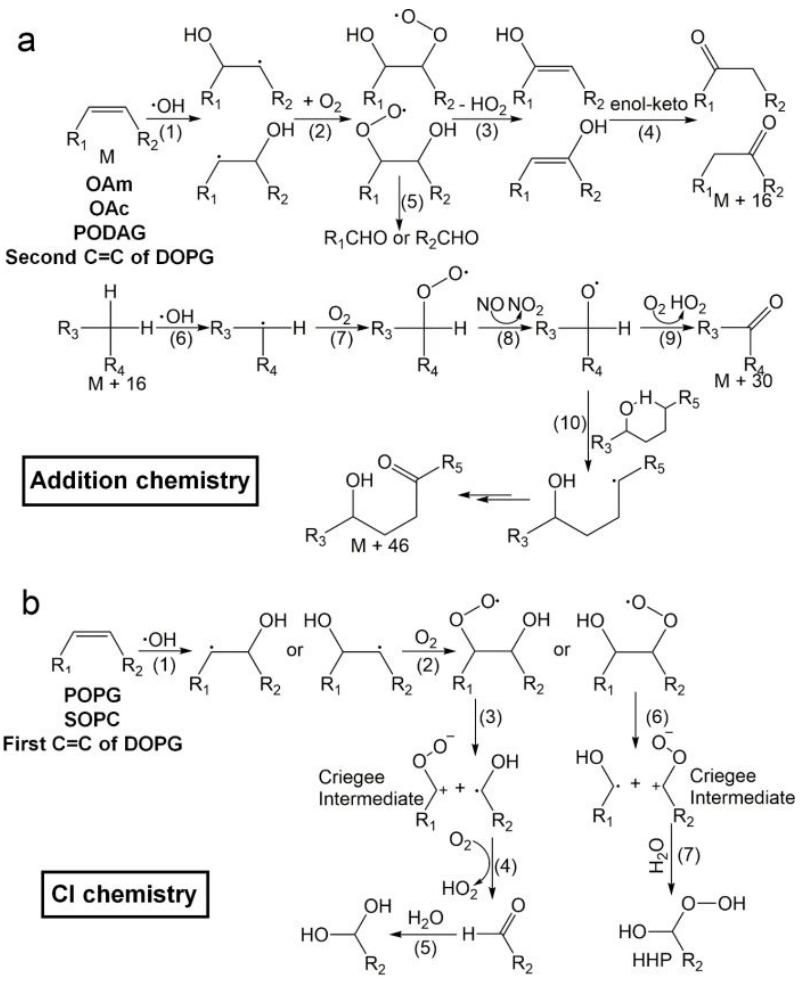

Figure 5. Proposed mechanisms of the addition chemistry (a) and CI chemistry (b).

We next discuss why the packing density completely determines these two different mechanisms. Figure 6 starts with a $\mathrm{C}=\mathrm{C}$ bond that belongs to any of the systems studied. The $\mathrm{O}_{2}$ molecule can attack the planer hydroxyalkyl radical from two directions, forming two enantiomeric hydroxyperoxy radicals. For the addition chemistry (red color shaded), the $\mathrm{O}_{2}$ moiety and adjacent $\mathrm{H}$ atom must contact to form the $\mathrm{HO}_{2}$ leaving molecule, this requiring eclipsed conformations. Note that both R1 and R2 are extremely bulky groups, indicating that the $\mathrm{C}-\mathrm{C}$ bond rotation in $3 \mathrm{D}$ to these eclipsed conformations is constrained in confined surroundings, and can only be achieved in a relatively loose environment where there is sufficient space to rotate. In contrast, for the tight environment (green color shaded), the R1 and R2 groups are constrained to a staggered conformation, preventing the $\mathrm{O}_{2}$ moiety and adjacent $\mathrm{H}$ atom from coming into close proximity. Instead, the chemistry can only occur in $1 \mathrm{D}$, yielding cleavage of the $\mathrm{C}-\mathrm{C}$ bond along the chain to generate the CI.

To explore the energetics associated with the CI and addition chemistries, potential energy surface calculations using $\mathrm{C}_{2} \mathrm{H}_{4}$ as a model system are presented in Figure 7 . The black lines denote the CI chemistry pathway that is similar to that of Reference 13, and the red lines denote the addition chemistry pathway. All of the structures are optimized at the $\omega \mathrm{B} 97 \mathrm{X}-\mathrm{D} / 6-311++\mathrm{G}(3 \mathrm{df}, 3 \mathrm{pd})$ level of theory with zero-point energy correction using the Gaussian09 package. Without constraints from the environment, the products formed in addition chemistry should have lower energy than its CI counterpart. It is indeed so as shown by Figure 7 . Even the transitions state (TS) of the enol-forming step along the addition chemistry pathway has lower energy than the CIforming step along the CI chemistry pathway, manifesting that addition chemistry is thermodynamically favored if it is not sterically hindered. 


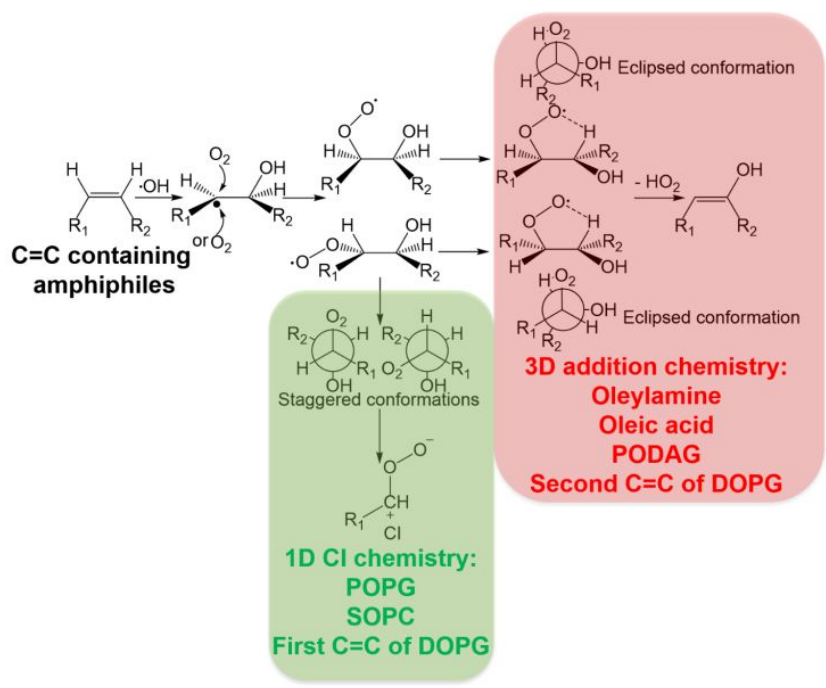

Figure 6. How difference in packing density changes the oxidation chemistry of the monolayer.

\section{Conclusion}

The $\mathrm{OH}$ oxidation chemistry of the monolayers formed by six different amphiphilic molecules and their mixtures at the air-water interface has been studied using the FIDI-MS methodology. The oxidation chemistry is delicately influenced by the packing densities of the hydrophobic appendages. The chemistry of relatively loosely packed OAm, OAc, PODAG, the second $\mathrm{C}=\mathrm{C}$ bond of $\mathrm{DOPG}, \mathrm{POPG} / \mathrm{OAm}$ mixture, and DOPG/OAm mixture complies with a patterned addition chemistry, where the $\mathrm{C}=\mathrm{C}$ double bonds are first oxidized into carbonyl groups, followed by the $\mathrm{C}-\mathrm{H}$ saturated bonds being oxidized to form additional carbonyl and hydroxyl groups. The addition chemistry pathway goes through a hydroxyperoxy radical, where the loosely packed environment allows eclipsed conformations so that the $\mathrm{O}_{2}$ moiety can contact the adjacent $\mathrm{H}$ atom to eliminate $\mathrm{HO}_{2}$ (Figure 5a and Figure 6). The oxidation chemistry of relatively densely packed POPG, SOPC and the first $\mathrm{C}=\mathrm{C}$ bond of DOPG conforms to the $\mathrm{CI}$ chemistry. The $\mathrm{C}=\mathrm{C}$ double bond is cleaved into an aldehyde molecule and an HHP molecule. In a similar hydroxyperoxy radical, only staggered conformations are allowed due to the densely packed environment (Figure 6), where the $\mathrm{O}_{2}$ moiety cannot contact the adjacent $\mathrm{H}$ atom, constraining the elimination of $\mathrm{HO}_{2}$. Instead, the chemistry can only occur along the 1D hydrocarbon chain, resulting in the $\mathrm{C}-\mathrm{C}$ bond cleavage.

For the first time the delicacy of the compositions of the surfactant/lipid composed monolayers has been revealed to have profound influence on the chemical reaction pathways. The $\mathrm{OH}$ oxidation chemistry of the $\mathrm{C}=\mathrm{C}$ double bond is a noteworthy chemomarker of the packing density of amphiphilic molecular layers.

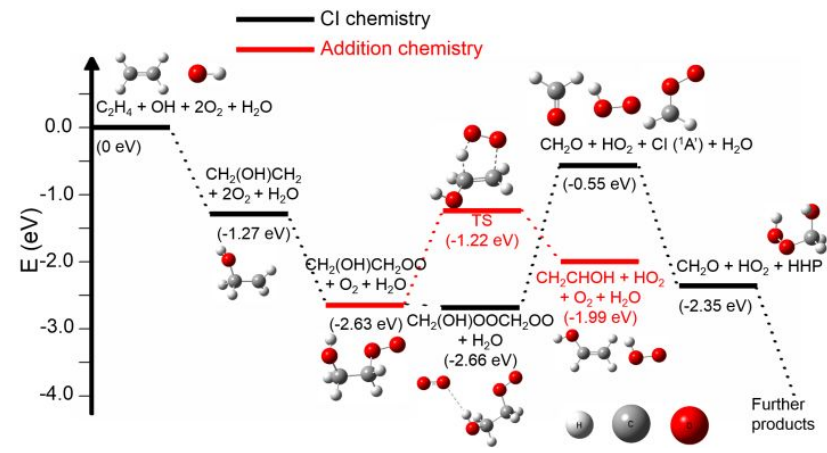

Figure 7. Reaction potential energy surfaces $(\mathrm{eV})$ for the $\mathrm{CI}$ and addition chemistries using ethylene as a model system at the $\omega \mathrm{B} 97 \mathrm{X}-\mathrm{D} / 6-311++\mathrm{G}(3 \mathrm{df}, 3 \mathrm{pd})$ level of theory.

\section{ASSOCIATED CONTENT}

Supporting Information

Additional distinct structures of six molecules and the schematic drawing of the FIDI-MS setup. This material is available free of charge via the Internet at http://pubs.acs.org.

\section{AUTHOR INFORMATION}

\section{Corresponding Author}

*zhangxx@nankai.edu.cn (X.Z.);

*jlbchamp@caltech.edu (J.L.B.)

\section{Notes}

The authors declare no completing financial interest.

\section{ACKNOWLEDGMENT}

This work was supported by the Beckman Institute at Caltech and by NSF grant CHE-1508825 (J.L.B.).

\section{REFERENCES}

(1) Nagarajan, R. Molecular packing parameter and surfactant self-assembly: the neglected role of the surfactant tail. Langmuir 2002, 18, 31-38.

(2). Bigay, J.; Antonny, B. Curvature, lipid packing, and electrostatics of membrane organelles: defining cellular territories in determining specificity. Dev. Cell 2012, 23, 886895.

(3) Lam1, S. M.; Tong, L.; Duan, X.; Petznick, A.; Wenk, M.; R.; Shui, G. Extensive characterization of human tear fluid collected using different techniques unravels the presence of novel lipid amphiphiles. J. Lipid Res. 2014, 55, 289-298.

(4) Szabo, G. Dual mechanism for the action of cholesterol on membrane permeability. Nature 1974, 252, 47-49.

(5) Mouritsen, O. G.; Zuckermann, M. J. What's so special about cholesterol? Lipids 2004, 39, 1101-1113.

(6) Simons, K.; Ikonen, E. H. How cells handle cholesterol. Science 2000, 290, 1721-1726.

(7) Tanford, C. The Hydrophobic Effect: formation of micelles and biological membranes; Wiley-Interface: New York, 1973.

(8) Li, S.; Lin, H.; Wang, Z.; Huang, C. Identification and characterization of kink motifs in 1-palmitoyl-2-oleoyIphosphatidylcholines: a molecular mechanics study. Biophys. $J$. 1994, 66, 2005-2018.

(9) Small, D. M. Lateral chain packing in lipids and membranes. J. Lipid. Res. 1984, 25, 1490-1500.

(10) Mathai, J. C.; Tristram-Nagle, S.; Nagle, J. F.; Zeidel, M. L. Structural determinants of water permeability through the lipid membrane. J. Gen. Physiol. 2008, 131, 69-76.

(11) Kaneko, F.; Yano, J.; Sato, K. Diversity in the fatty-acid 
conformation and chain packing of cis-unsaturated lipids. Curr. Opin. Struct. Biol. 1998, 8, 417-425.

(12) Sànchez, S. A.; Tricerri, M. A.; Ossato, G.; Gratton, E. Lipid packing determines protein-membrane interactions: challenges for apolipoprotein A-I and high density lipoproteins. Biochim. Biophys. Acta. 2010, 1798, 1399-1408.

(13) Zhang, X.; Barraza, K.; Beauchamp, J. L. Cholesterol provides non-sacrificial protection of membrane lipids from chemical damage at air-water interface. Proc. Natl. Acad. Sci. 2018, 115, 3255-3260.

(14) Atkinson, R.; Arey, J. Atmospheric degradation of volatile organic compounds. Chem. Rev. 2003, 103, 4605-4638.

(15) Patil, G. S.; Matthews, R. H.; Cornwell, D. G. Estimation of surface area and counterion binding characteristics in fatty amine monolayers from desorption kinetics. J. Lipid Res. 1976, 17, 197-202.

(16) Das, S.; Rand, R. P. Modification by diacylglycerol of the structure and interaction of various phospholipid bilayer membranes. Biochemistry 1986, 25, 2882-2889.

(17) Pan, J.; Heberle, F. A.; Tristram-Nagle, S.; Szymanski, M.; Koepfinger, M.; Katsaras, J; Kučerkae, N. Molecular structures of fluid phase phosphatidylglycerol bilayers as determined by small angle neutron and X-ray scattering. Biochim. Biophys. Acta. 2012, 1818, 2135-2148.

(18) Kučerka, N.; Nieh, M. -P.; Katsaras, J. Fluid phase lipid areas and bilayer thicknesses of commonly used phosphatidylcholines as a function of temperature. Biochim. Biophys. Acta. 2011, 1808, 2761-2771.

(19) Marty. J. C.; Saliot, A.; Buat-Menard, P.; Chesselet, R; Hunter, K. A. Relationship between the lipid compositions of marine aerosols, the sea surface microlayer, and subsurface water. J. Geophys. Res. 1979, 84, 5707-5716.

(20) Nkadi, P. O.; Merritt, T. A.; Pillers, D.-A. M. An overview of pulmonary surfactant in the neonate: Genetics, metabolism, and the role of surfactant in health and disease. Mol. Genet. Metab. 2009, 97, 95-101.

(21) Montzka, S. A.; Krol, M.; Dlugokencky, E.; Hall, B.; Jöckel, P.; Lelieveld, J. Small interannual variability of global atmospheric hydroxyl. Science 2011, 331, 67-69.

(22) Karam, L. R.; Bergtold, D. S.; Simic. M. G. Biomarkers of $\mathrm{OH}$ radical damage in vivo. Free. Radic. Res. Commun. 1991, 12, 11-16.

(23) Sies, H. Strategies of antioxidant defense. Euro. J. Biochem. 1993, 215, 213-219.

(24) Grimm, R. L.; Beauchamp, J. L. Field-induced droplet ionization mass spectrometry. J. Phys. Chem. B 2003, 107, 14161-14163.

(25) Grimm, R. L.; Beauchamp, J. L. Dynamics of field-induced droplet ionization: time-resolved studies of distortion, jetting, and progeny formation from charged and neutral methanol droplets exposed to strong electric fields. J. Phys. Chem. B 2005, $109,8244-8250$.

(26) Zhang, X.; Barraza, K. M.; Upton, K. T.; Beauchamp, J. L. Time resolved study of hydroxyl radical oxidation of oleic acid at the air-water interface. Chem. Phys. Lett. 2017. 683, 76-82.

(27) Criegee, R. Mechanism of ozonolysis. Angew. Chem. Int. Ed. Engl. 1975, 14, 745-752.

(28) Ko, J. Y.; Choi, S. M.; Rhee, Y. M.; Beauchamp, J. L.; Kim, H. I. Studying interfacial reactions of cholesterol sulfate in an unsaturated phosphatidylglycerol layer with ozone using field induced droplet ionization mass spectrometry. J. Am. Soc. Mass Spectrom. 2012, 23, 141-152.

(29) Novelli, A.; Vereecken, L.; Lelieveld, J.; Harder, H. Direct observation of $\mathrm{OH}$ formation from stabilised Criegee intermediates. Phys. Chem. Chem. Phys. 2014, 16, 19941-19951. (30) Nah, T.; Kessler, S. H.; Daumit, K. E.; Kroll, J. H.; Leone, S. R.; Wilson, K. R. OH-initiated oxidation of sub-micron unsaturated fatty acid particles. Phys. Chem. Chem. Phys. 2013, $15,18649-18663$.

(31) Westerdahl, D.; Fruin, S.; Sax, T.; Fine, P.M.; Sioutas, C. Mobile platform measurements of ultrafine particles and associated pollutant concentrations on freeways and residential streets in Los Angeles. Atmos. Environ. 2005, 39, 3597-3610.

(32) Finlayson-Pitts, B. J.; Pitts, J. N. Jr. Chemistry of the Upper and Lower Atmosphere; Academic Press: USA, 2000.

(33) Nehr, S.; Bohn, B.; Fuchs, H.; Hofzumahaus, A.; Wahner, A. $\mathrm{HO} 2$ formation from the $\mathrm{OH}+$ benzene reaction in the presence of O2. Phys. Chem. Chem. Phys. 2011, 13, 1069910708.

(34) King, M.D.; Thompson, K. C. Rate constants for the reaction of $\mathrm{NO}$ and $\mathrm{HO} 2$ with peroxy radicals formed from the reaction of $\mathrm{OH}, \mathrm{Cl}$ or $\mathrm{NO} 3$ with alkenes, dienes and $\alpha, \beta$ unsaturated carbonyls. Atmos. Environ. 2003, 37, 4517-4527.

(35) Calvert, J.; Derwent, R. G.; Orlando, J. J.; Tyndall, G. S.; Wallington, T. J. Mechanisms of atmospheric oxidation of the alkanes; Oxford University Press: USA, 2008.

(36) Chao, W.; Hsieh, J.-T.; Chang, C.-H.; Lin, J. J.-M. Direct kinetic measurement of the reaction of the simplest Criegee intermediate with water vapor. Science 2015, 347, 751-754.

(37) Tobias, H. J.; Ziemann, P. J. Kinetics of the gas-phase reactions of alcohols, aldehydes, carboxylic acids, and water with the $\mathrm{C} 13$ stabilized Criegee intermediate formed from ozonolysis of 1-tetradecene. J. Phys. Chem. A 2001, 105, 61296135 . 
1
2
3
4
5
6
7
8
9

9

10

11

12

13

14

15

16

17

18
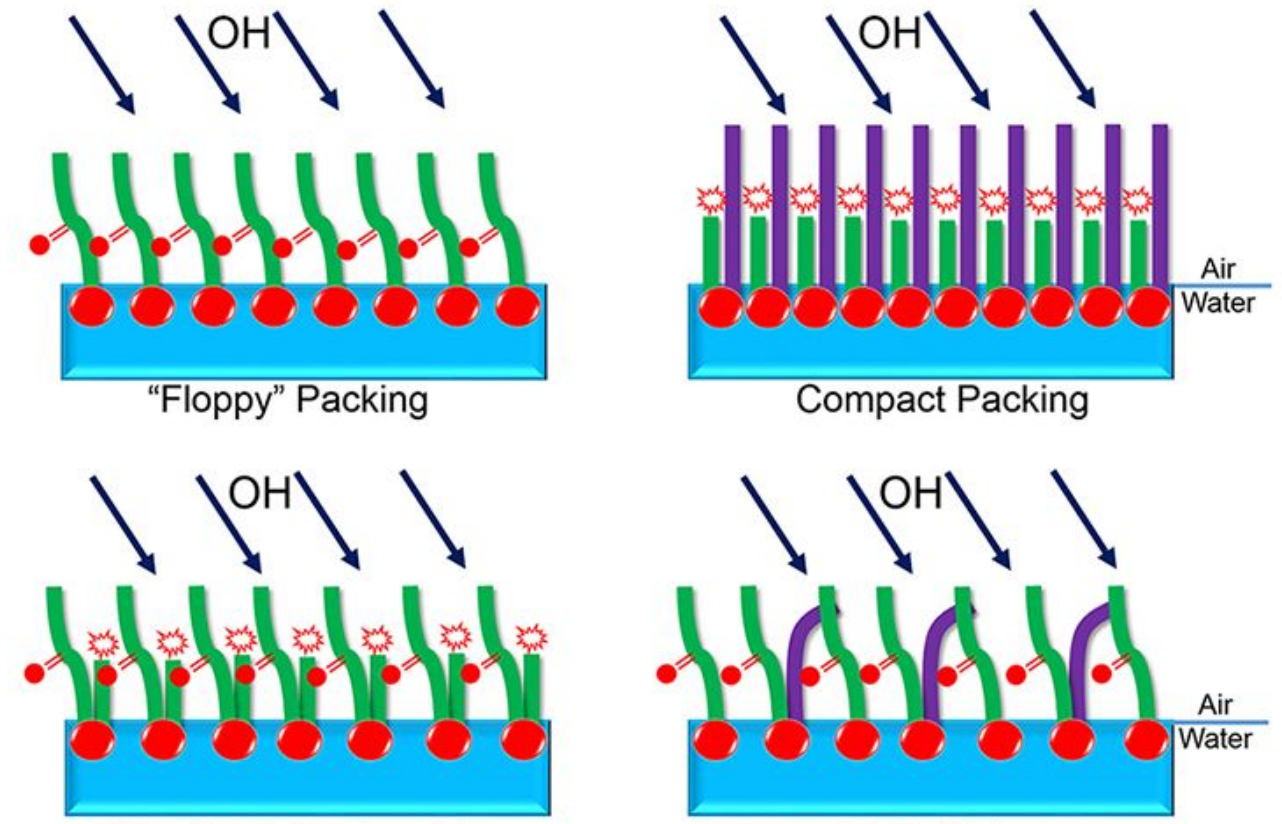

Pirior Oxidation Involving $\mathrm{C}=\mathrm{C}$ Cleavage

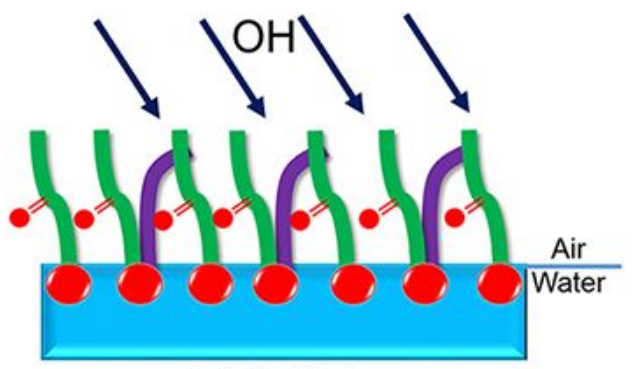

Lipid Mixture 
$\bullet \quad$ Carbonyl group C=C cleavage
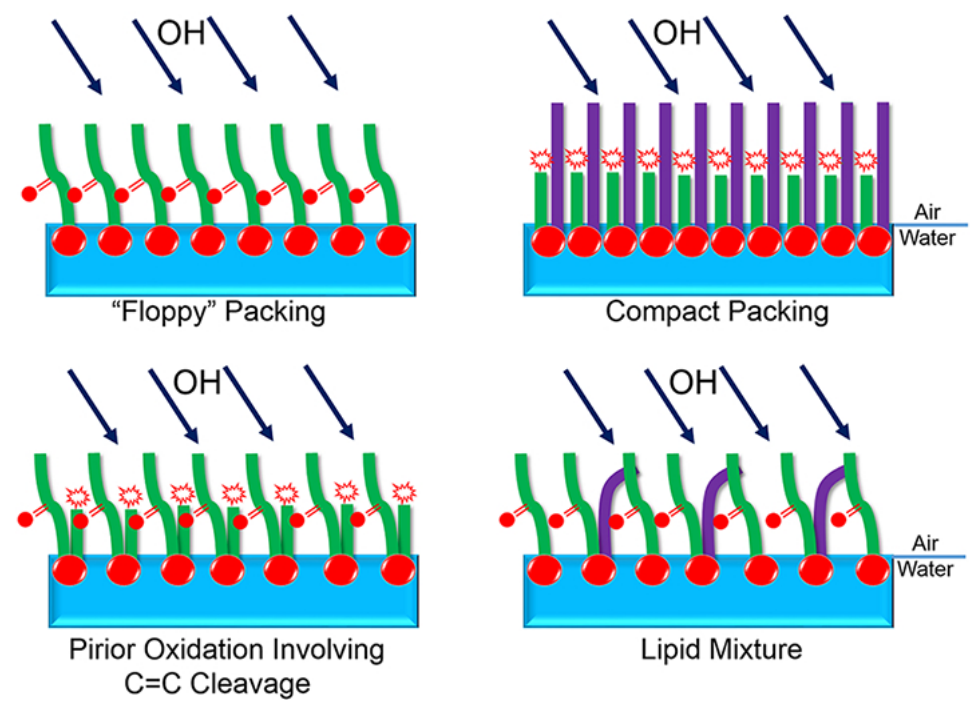

Lipid Mixture

$82 \times 44 \mathrm{~mm}(300 \times 300$ DPI $)$ 